\title{
Flipping the model for access to patient records
}

NHS England would like to make it clear that care.data is a separate project to the online GP records programme. The online GP records system is an ongoing process with a defined end date of completion (2018) that will allow patients online access to their medical records from their GP practice.

This programme is not running under the care.data remit, which will be storing medical data from NHS patients on a central database managed by HSCIC and using this as a real world data tool. The timeline for the completion of this project has not been set by NHS England. NHS England said that care.data is not the "IT change programme" as stated in the original feature (BMJ 2016;352:i722, doi:10.1136/bmj.i722).

NHS England declined to allow the author to speak to the care.data team directly for this feature. The HSCIC also declined to allow any members of the team responsible for care.data to be interviewed for this piece. 